\title{
Article \\ Inter-Municipal Methodology for Climate Transition Strategies: The First Case in Italy
}

\author{
Giovanni Litt ${ }^{1}\left(\right.$, Elena Ferraioli $\left.{ }^{1, *} \mathbb{(}\right)$, Filippo Magni ${ }^{2}\left(\mathbb{D}\right.$, Giulia Lucertini $^{2}\left(\mathbb{D}\right.$ and Francesco Musco ${ }^{2}(\mathbb{D}$ \\ 1 Department of Architecture and Arts, Iuav University of Venice, 30135 Venice, Italy; giovanni.litt@iuav.it \\ 2 EPiC Earth and Polis Research Centre, Department of Architecture and Arts, Iuav University of Venice, \\ 30135 Venice, Italy; filippo.magni@iuav.it (F.M.); giulia.lucertini@iuav.it (G.L.); francesco.musco@iuav.it (F.M.) \\ * Correspondence: elena.ferraioli@iuav.it; Tel.: +39-348-29-19-966
}

Citation: Litt, G.; Ferraioli, E.; Magni, F.; Lucertini, G.; Musco, F. Inter-

Municipal Methodology for Climate Transition Strategies: The First Case in Italy. Sustainability 2022, 14, 2529. https://doi.org/10.3390/su14052529

Academic Editor: Lirong Liu

Received: 14 December 2021

Accepted: 17 February 2022

Published: 22 February 2022

Publisher's Note: MDPI stays neutral with regard to jurisdictional claims in published maps and institutional affiliations.

Copyright: () 2022 by the authors Licensee MDPI, Basel, Switzerland. This article is an open access article distributed under the terms and conditions of the Creative Commons Attribution (CC BY) license (https:// creativecommons.org/licenses/by/ $4.0 /)$.

\begin{abstract}
To build resilient and climate-neutral cities, it is required to modify current territorial planning processes to make them more sustainable and virtuous. However, the implementation of new strategies and innovative governance models faces multiple obstacles, economic restrictions, and technical gaps. In particular, local governments often find it difficult to build structured transition processes. This article investigates how it is possible to respond effectively to the need of urban contexts to adapt to climate impacts, analyzing the case of the Climate Transition Strategy (CTS) "La Brianza Cambia Clima", the first in Italy of this kind. Through the technical framework and the methodology described, the CTS can activate inter-municipal transformative actions through the mainstreaming of planning tools, the construction of a medium-long-term vision, and the identification of concrete and widespread actions to be implemented in the territory. This coordinated and shared strategic approach allows one to give stability, coherence, and continuity to adaptation processes involving different stakeholders and sectors of the Public Administration. Finally, it favors the implementation of multidisciplinary policies for territorial resilience on a large scale.
\end{abstract}

Keywords: climate transition; transition strategies; inter-municipal strategies; methodological framework; climate-neutral cities; resilient cities; local administrations; climate change

\section{Introduction}

Climate Change (CC) is contributing to the worsening of inhabitants' living conditions and to the reduction in the capacity of territories to face shocks and stresses [1]. Italy and the entire Mediterranean basin fall within one of the hotspots defined as most vulnerable to future impacts [2]. This requires an urgent modification of consolidated approaches to spatial planning, both in terms of reducing the production of climate-changing emissions $[3,4]$ and increasing the resilience of urban systems to progressive climate variability [5]. The adaptation of territories to climate impacts must therefore become a process that integrates with the urban planning tools in force [6] and that, alongside the current models of development and management, also guides reflections and decisions on climate. This process aiming to build climate-neutral and resilient cities [7] must involve a comprehensive commitment in every aspect of spatial management and dynamics [8] and can only be achieved through a coordinated and integrated engagement [9]. Despite many current efforts, administrations, especially medium and small ones, often struggle to define integrated solution approaches and to build climate change adaptation pathways on their own [10].

These difficulties are due to some main gaps:

1. Lack of a coherent and updated knowledge framework [11]: up-to-date and specific knowledge is essential to plan appropriate and effective compensatory actions;

2. Lack of a territorial and inter-municipal vision: adaptation and mitigation policies are usually only developed municipally, when CC impacts would otherwise often involve a wider territorial context, so responses to these gaps should be planned in an equally wide context [12]; 
3. Lack of technical knowledge due to economic restrictions;

4. Lack of holistic, multilevel, and interdisciplinary solutions: adaptation and mitigation actions are relegated to specific plans and are not able to interface with mandatory planning [13].

As a consequence of that, small- and medium-sized Italian municipalities are not able to develop integrated climate transition processes. Although Sustainable Energy Action Plans (SEAPs) are widespread in Italy (more than 3000), this does not include the new Sustainable Energy and Climate Action Plans (SECAPs) or other Climate Adaptation Plans or Resilience Strategies that only major cities have adopted in the last few years.

Thus, how would it be possible to help Italian small- and medium-sized municipalities in filling technical and implementational gaps? Why is it advisable to act at the intermunicipal level to initiate Climate Transition processes? How can the intentions of several administrations be united under a common strategy and methodology? Starting from these questions, this paper analyzes the methodology carried out in the implementation case of the Climate Transition Strategy (CTS) "La Brianza Cambia Clima", the first in Italy of this kind.

The paper is structured as follows: first, the paper presents the case study; then, it describes the methodology developed to define the CTS and how this is linked with international frameworks on adaptation. Finally, before the discussion and results, the paper outlines the steps that constitute the CTS, highlighting the potential toward climate transition.

\section{The Call for Ideas "Strategia Clima" and the Application Case: West Brianza (Italy)}

Regarding CC, resilience, and territorial sustainability in Italy, it is important to highlight the activities carried out by Fondazione Cariplo (FC), a former banking foundation that has been supporting and promoting the implementation of many initiatives to combat CC for 30 years. In 2019, FC launched the project "F2C_Fondazione Cariplo per il Clima" [14] to give life to a more organic and structured strategy in the field of environmental sustainability through interventions for the decrease in climate-changing emissions, mitigation of the impacts of extreme weather phenomena, and an increase in natural capital. In the context of this specific project, the Call for Ideas "Strategia Clima" (described in detail in Appendix A) was born to promote and support initiatives aiming to define mitigation and adaptation actions to CC to activate processes of the Climate Transition Strategy at the local level. With this initiative, FC wanted to build on previous experiences to address a complex issue such as CC with an experimental approach aimed at local level policies. In this sense, the Call aims to select territorial partnerships for support, through a technical assistance service and a Technical Scientific Committee (TSC), in the co-design of a CTS and in the implementation of some targeted interventions.

Based on the specific criteria of the Call-relation to the objectives of the F2C project, project interventions consistent with the territorial context, innovative, and replicable, suitable governance structure, solid medium-long-term vision and support from other territorial subjects and stakeholders - the first project idea has been identified, selected among nine proposals received, to develop a CTS. Among the nine proposals, six came from aggregations of municipalities and three from individual municipalities, but the first selected, for the highest score resulting from the criteria of the Call, was West Brianza (in the north of the city of Milan) (Figure 1). In 2020, the whole partnership consisting of the municipalities of Cesano Maderno, Bovisio Masciago, Meda and Varedo, the Parco Regionale delle Groane e della Brughiera Briantea (a regional protected area of 7700 hectares), the Civil Protection Group of Cesano Maderno, the InnovA21 Agency, and the Fondazione Lombardia per l'Ambiente (FLA) set-up a draft project called "La Brianza Cambia Clima". 


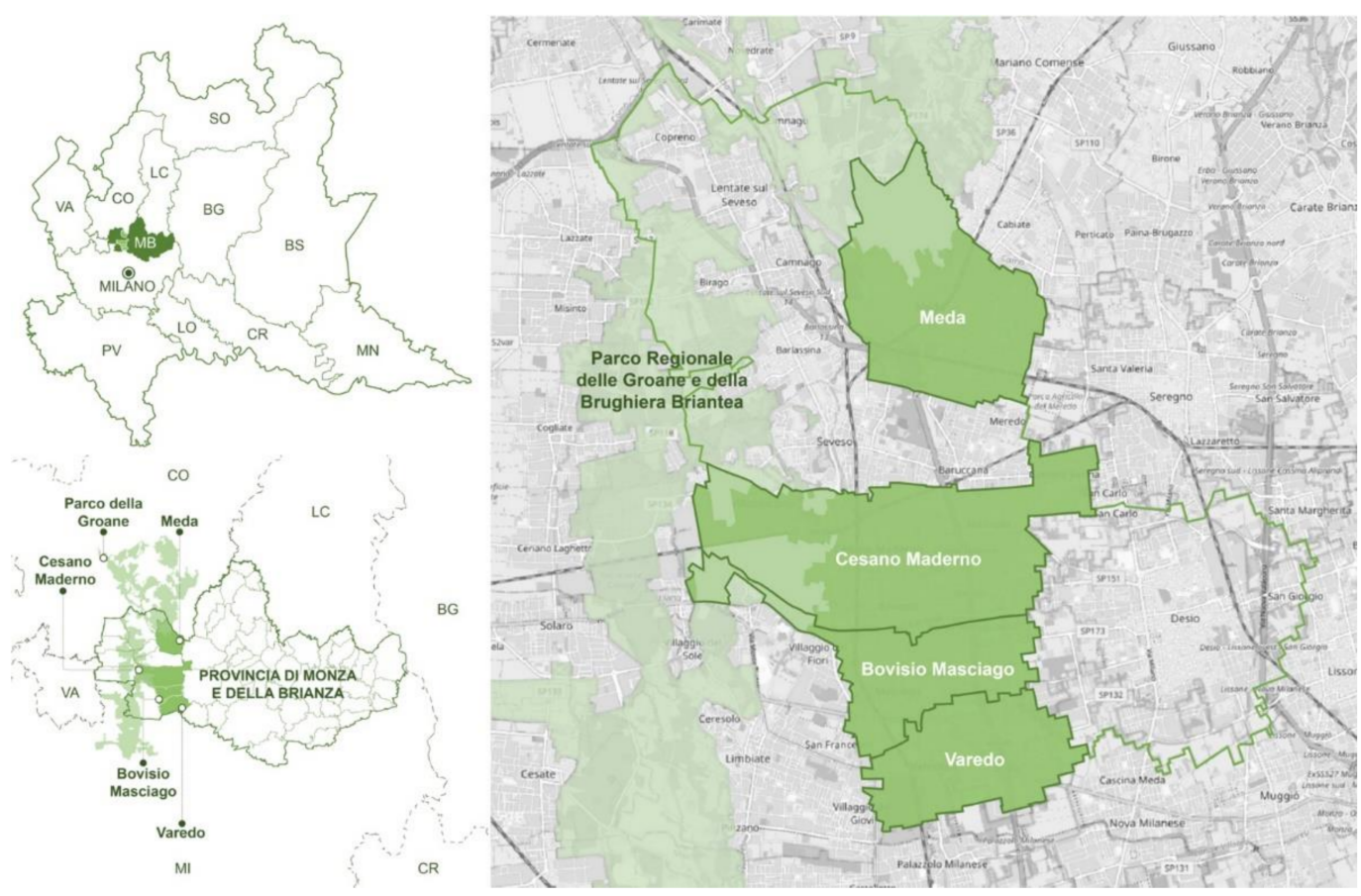

Figure 1. Location of the four municipalities included in the project area and the Parco delle Groane e della Brughiera Briantea.

The project ideas were later processed thanks to the cooperation between FC, the technical assistance group (set-up by the Iuav University of Venice and Ambiente Italia), the Scientific Committee (composed of university professors of forestry and urban planning from Polytechnic of Milan and Turin, technical experts of national and local bodies, such as ISPRA and Fondazione Osservatorio Meteo Duomo Milano), and the involvement of the Lombardy Region and various local players. This collaborative and shared process was made to promote West Brianza as a laboratory for experimentation for inter-municipal policies and tools.

\section{Methodology}

The Call for Ideas "Strategia Clima" (Appendix A), funded by an initial budget of EUR $2,200,000$, wants to support the drafting of the CTS and the subsequent implementation of adaptation and mitigation interventions to climate change in municipalities that, until now, have not been able to adopt Climate Transition Plans, due to the above-mentioned restrictions. The approach designed within the Call to develop local CTSs is based on established theories that draw on internationally agreed methodologies based on which the UNFCCC has developed a theoretical framework on adaptation [15,16]. This framework is a practical and specific guide to support local, regional, and national decision-making bodies, structured in the following macro-steps [17]:

- $\quad$ Build a knowledge base on adaptation;

- Assess the impacts of climate change at macro and micro levels;

- Assess vulnerability and relative adaptive capacity;

- Identify possible adaptation options (design of adaptation measures);

- Implementation of measures;

- Monitoring and evaluation of effectiveness.

The methodology developed to accompany the construction of this CTS was defined considering the UNFCCC indications and methodological experiences developed within previous virtuous projects and initiatives (shown in Figure 2). The methodology for the CTS of "La Brianza Cambia Clima" was developed in five main steps (Figure 2): 
1. Definition of the coordination structure and tools: building a direction able to give continuity to the initiatives, to open up to the territory, and to create the best conditions for its further development and implementation.

2. Construction of a knowledge framework: starting an integrated analysis that takes into account demographic, economic, climatic, and energy aspects in order to assess the impacts and consequences that the new climate scenarios will determine on the territory.

3. Construction of a common vision and strategic goals: defining an overall strategic vision, based on the synthesis of existing local and wide area plans, aiming to provide a reference framework and a long-term projection for the territories considered, as well as defining priority lines of action for future integrated development adapted to local climate conditions.

4. Improvement of planned actions in a resilient perspective: transforming theoretical indications into a synergic framework of functional actions for the achievement of the set of strategic macro-objectives, which are the result of a shared planning among the different local authorities and administrations and derive from an in-depth analysis of the cognitive framework, the level of priority, and the degree of political and economic feasibility of the interventions themselves.

5. Mainstreaming local planning: integrating the concept of mainstreaming [18] (inclusion of climate aspects in development programs, policies, or management strategies) into the development and governance dynamics of partner municipalities, to transfer the objectives of superordinate planning to local planning, to promote the intersectoriality of local instruments and policies, and to harmonize administrative procedures on adaptation and mitigation.

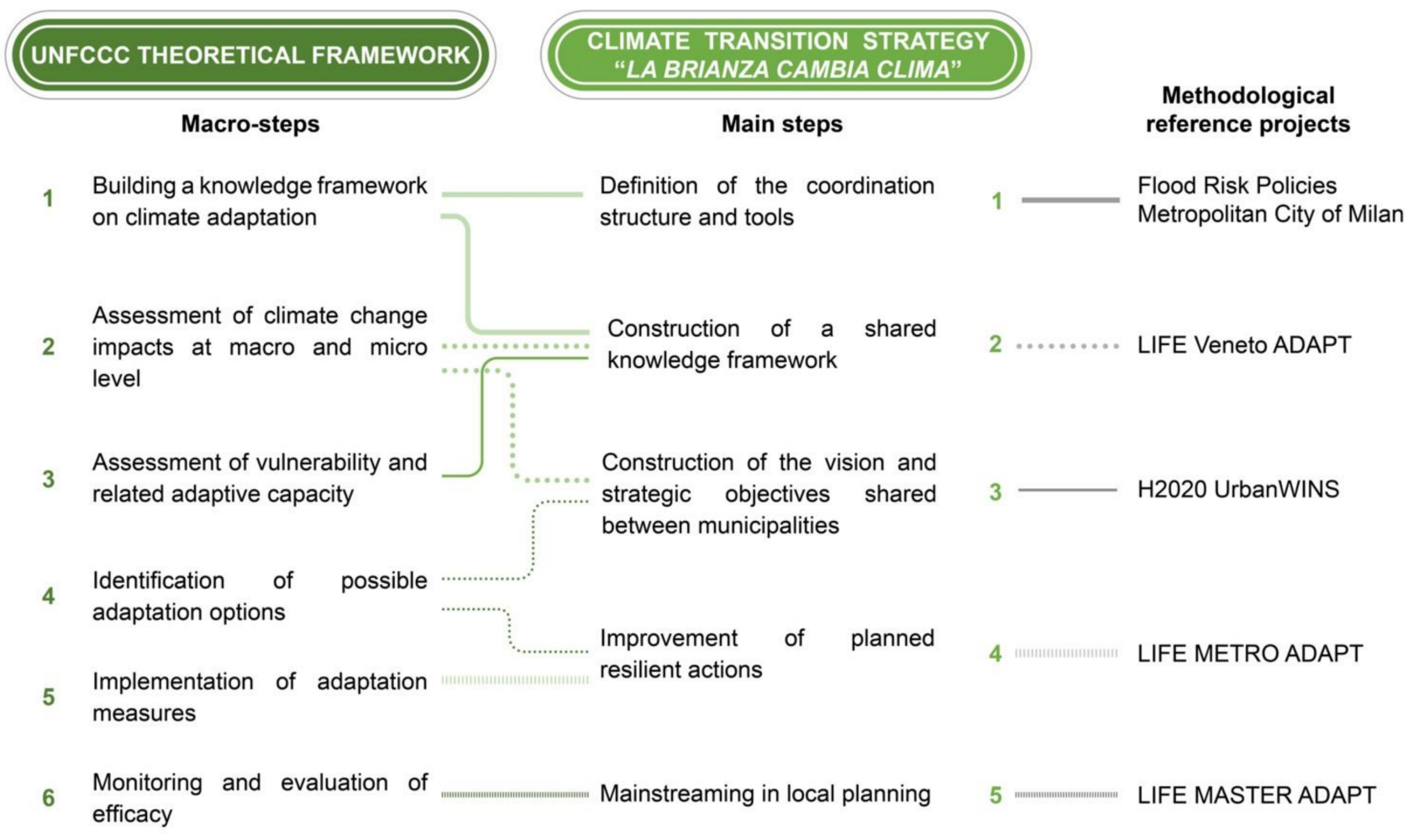

Figure 2. The main steps of the CTS "La Brianza Cambia Clima" compared with the UNFCCC theoretical framework and methodological reference projects.

As Figure 2 schematically explains, the structure of the CTS starts from the methodological indications of the UNFCCC that are contextualized in the specific territory. Each of the five steps, then, is deepened with methodologies developed in territories similar or 
comparable for physical or administrative characteristics to those of West Brianza. Particularly significant for their replicability in the study area are the examples of the Flood Risk Policies of the Metropolitan City of Milan [19] together with the recently developed LIFE projects dealing with CC adaptation and mitigation [20-22].

The articulated process defined in the previous paragraph has been developed with many unilateral or Steering Committee meetings within several months of work (Appendix B). For each of the five points of the process, a shared path was developed: (i) with the Cabina di Regia; (ii) with the municipalities involved in the individual actions; (iii) with the Technical Scientific Committee (TSC) for a final validation. In this way, the CTS was validated both with the implementers (the municipalities) and with those responsible for methodological consistency (the STC).

The validation of the methodological framework is entrusted to a specific section of the CTS that defines a monitoring plan. This evaluates: (i) the monitoring of the implementation of individual actions planned in the short- and medium-term (2021-2023); (ii) the analysis of the achievement of medium- and long-term strategic objectives (2021 and future updates); (iii); the continuous updating of the context for the aspects of greatest relevance to the CTS. In this way, both verifications of the performance of the objectives and actions (thanks to context, process, and result indicators) and verification of the effectiveness and efficiency of the CTS are foreseen.

\section{Results}

In this way, the CTS "La Brianza Cambia Clima" tried to solve the main criticalities indicated at the beginning. Starting from deep territorial analysis and a clear and shared definition of the goals, the CTS intends to activate inter-municipal policies and tools in West Brianza, through the identification of concrete actions aimed at carrying out a series of widespread interventions in the territory capable of generating multiple local and large-scale benefits, making revisions to urban planning tools, increasing the moments of training and mutual exchange between Public Administrations, and collaboration between institutions and the local community to develop further innovative projects in the territory. The CTS should be conceived as an operational tool able to directly affect all decisionmaking processes of the Public Administration and indirectly those of private parties. The CTS should direct both the definition of new urban development policies and the regulatory and implementation planning tools, as well as the allocation of public funds for the implementation of interventions on an urban and territorial scale. Therefore, this chapter presents the results of each methodological step toward the construction of the CTS. It describes how the following steps lead to transformative results toward climate transition for West Brianza:

- Definition of the coordination structure and tools;

- Construction of a knowledge framework;

- Construction of a common vision and strategic goals;

- Improvement of planned actions in a resilient perspective;

- Mainstreaming local planning.

\subsection{Definition of the Coordination Structure and Tools}

The Call for Ideas wants to promote a stable and lasting change to the territory that is equipped with a CTS. In order to ensure this, the CTS created the following:

- The Climate Transition Steering Committee (CTSC) is based on a coordinator and contact persons for each partner authority;

- The action of maintaining the network, which guarantees operability and constant dialogue between all partners, also through the support function of the InnovA21 Agency;

- The preliminary stakeholder mapping that supports the definition of networking activities toward other municipalities and other institutional levels, which are configured as resources to be developed in synergy with the Communication actions for the project 
refinement process, and the collection of new ideas and allies for the implementation of the CTS;

- The Monitoring Plan, which is proposed as a tool to follow the development of individual actions over time and to strengthen their capacity to contribute to the overall vision and to collect and stimulate other virtuous developments on the territory, consistent with the CTS;

- The action of searching for funding aims to guarantee the partnership (and its desirable extension to other subjects), the resources needed to nurture new project ideas, and to concretely implement new actions and solutions.

\subsection{Construction of a Knowledge Framework}

The CTS has produced several cognitive outputs that were lacking in the municipalities involved and, without which, it was difficult for public administrations to initiate climate transition processes. The analyses carried out are the following:

- A framework and account of territorial dynamics: it includes the networks that structures the macro-area context, the provincial economic framework, a demographic analysis per municipality, and a wide area economic analysis;

- A climate profile from the regional to the local scale and a subsequent definition of local-scale impacts deriving from climate change;

An analysis of the local energy system includes: the energy demand analysis, the energy supply analysis of the area, and the local emissions inventory.

The result of the territorial analysis highlights a great potential for strategies and actions aimed at the mitigation of climate-altering emissions, the re-naturalization and management of river and wooded areas, the development of de-watering, sustainable drainage, and greening interventions in urban contexts, and the activation of awareness and virtuous behaviors of PA, enterprises, and citizens.

\subsection{Construction of a Common Vision and Strategic Goals}

The Strategy, starting from a deep territorial analysis, develops a clear and shared definition of the goals, the precise identification of the process steps, and the systematic introduction of the logic and principles of climate mitigation and adaptation in the planning tools in force to achieve a real transition toward the resilience of territories capable of lasting over time.

The vision of "La Brianza Cambia Clima" is based on two pillars supported by five goals (Figure 3), around which the actions have been defined to support West Brianza in the climate transition process. To have the greatest territorial adherence and continuity of intentions with the stratified commitments of the partners, pillars and goals of the CTS have been outlined in coordination with the initiatives and the local plans already started in the territory of West Brianza to promote sustainable development and adaptation and mitigation to CC. As Appendix B shows, the vision has been validated several times by all stakeholders involved. These initiatives, as well as Local Government Plans, wide-area plans, and National and Regional Strategies for Adaptation to Climate Change, include the LIFE MASTER ADAPT project [20], the Seveso River Contract [23], and the Charter for action by the municipalities of the Seveso river basin toward local adaptation to CC [24]. This vision can permeate all the actions of the adhering municipalities, initiating the mainstreaming [13] of planning and design processes toward a climate-proof and resilient territory [10] in the medium-long term. Otherwise, the vision must also be shared and co-participated by citizens, the third sector, and companies, in the awareness that everyone can contribute to the commitment that the territory has undertaken [25]. In some cases, the goals contribute to several pillars, just as some actions contribute to achieving several objectives. This is because the actions have been designed to be as multifunctional and multi-scalar as possible and to contribute to increasing the capacity building of the Public Administration and the private and associative sectors. 


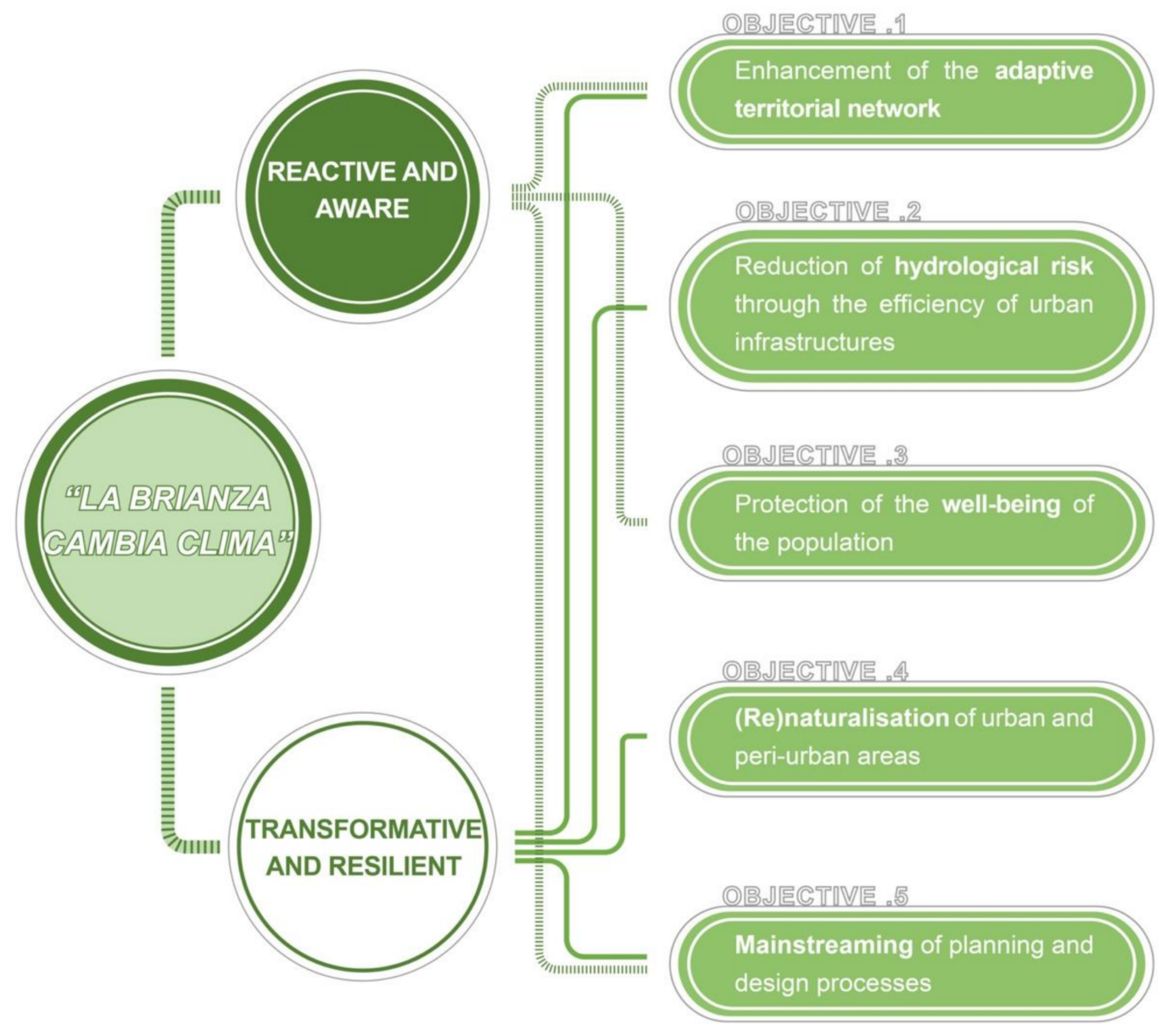

Figure 3. Example diagram of the vision.

\subsection{Improvement of Planned Actions in a Resilient Perspective}

Following the territorial analysis that has identified priorities for action and indications on which environmental and climatic criticalities to address, some pilot actions have been defined.

The CTS organizes and collects various types of measures, which include both territorial actions and punctual interventions falling within individual municipal territories and therefore having an immediate impact on the quality of life of local communities and integrated and multidisciplinary actions, aiming to develop a unitary strategy characterized by an inter-municipal vision, able to solve and mitigate critical issues thanks to a multiobjective and transversal approach. Overall, the Strategy includes 12 territorial actions distributed in four different operational fields and 8 governance actions, concerning information, training, integrated policies, communication, territorial identity, and development of cultural awareness and knowledge of the territory.

Specifically, the territorial actions contribute to responding in a synergic way to the strategy's guidelines, showing the different degrees of attention, maturity, and implementation of the interventions implemented in the individual territorial contexts. These refer to specific priority areas of intervention, such as sustainable water management, river rehabilitation and hydraulic safety, renaturation and creation of ecological value, and finally, sustainable mobility. As far as the methodological actions of governance are concerned, these are measures that involve the whole territory, in an integrated, inter-municipal, and wide-area perspective and that, in terms of approach and methodology, concern initiatives that cannot be territorialized and that can potentially be replicated in a perspective of effective governance. Each measure, both territorial and governance, is described in a fact sheet, an operational tool that gathers synthetic and summary information on interventions 
and achievements, to define and suggest strategic indications for the development of the action. Therefore, through an initial synthetic outline and a series of descriptive paragraphs, the sheet outlines the insertion of the intervention in the current territorial logic, specifying the areas of interest in terms of climate impacts, macro-objectives, and strategic directions to be followed. The goals and expected benefits are also identified, both in qualitative and quantitative terms, as well as the provision of possible indicators useful to monitor the results produced by the specific action, and therefore to quantify the effectiveness of the action concerning the vulnerability of the territory. Moreover, a specific indication is included on possible future long-term developments, both from an operational point of view and with a view to future inclusion in territorial government instruments. Finally, the lines of coherence that each specific action should have with the strategic and regulatory framework in force are indicated. To complete the sheets, in-depth studies are included on the stakeholder involvement activities and the relations with the specific communication and territorial involvement actions outside the partnership of the entire strategy.

All the actions aim to achieve six main goals (Figure 4):

1. Revision of urban planning instruments (Action 1): to promote an increasingly systematic introduction of the logic and principles of climate mitigation and adaptation into existing planning tools;

2. Climate Change adaptation and mitigation (Actions 2 to 13): to put into practice in various contexts the principles of sustainable urban drainage, river rehabilitation, naturalization of forest contexts, and integration of green areas in urban spaces, along with active mobility networks. All these actions are, therefore, experiences to be consolidated and further improved, to be used as pilot actions and to be multiplied;

3. Search for funding (Action 14): to activate future developments on various types of action that can be activated by PA;

4. Development of networks and tools for updating climate-relevant knowledge (Action 15): to create greater awareness, collaboration, predictive, and operational capacity of all stakeholders relevant to the CTS;

5. Capacity building and technical training (Action 16): to consolidate opportunities for stimulation, exchange, and professionalization in the PA;

6. Citizenship involvement and communication (Action 17 and 18): to spread and multiply the basic principles of the CTS.

The actions, located in a reasoned way based on the cognitive framework, produce results that contribute to the climate-neutrality and territorial resilience of West Brianza (Table 1):

Table 1. CTS actions and quantification of results.

\begin{tabular}{|c|c|c|c|}
\hline Action & Title & Indicators & $\begin{array}{l}\text { Quantification of Results } \\
\text { Expected (Minimum } \\
\text { Requirement) }\end{array}$ \\
\hline 1 & $\begin{array}{l}\text { Review of urban planning } \\
\text { instruments }\end{array}$ & $\begin{array}{l}\text { Mainstreamed planning instruments } \\
\text { Adaptation and mitigation measures } \\
\text { Definition of area targets for monitoring }\end{array}$ & $\begin{array}{l}4 \\
- \\
-\end{array}$ \\
\hline 2 & $\begin{array}{l}\text { Replacement of the paving of the } \\
\text { cemetery area }\end{array}$ & $\begin{array}{l}\text { Increase in the de-waterproofed area } \\
\text { Subtraction of volume to surface runoff } \\
\text { Improvement of runoff coefficient }\end{array}$ & $\begin{array}{c}7500 \mathrm{~m}^{2} \\
5200 \mathrm{~m}^{3} / \text { year } \\
\text { From } 0.9 \text { to } 0.6\end{array}$ \\
\hline 3 & Redevelopment of the market area & $\begin{array}{l}\text { Increase in the de-waterproofed area } \\
\text { Subtraction of volume to surface runoff } \\
\text { Improvement of the runoff coefficient } \\
\text { Increase in planting } \\
\mathrm{CO}_{2} \text { absorbed }\end{array}$ & $\begin{array}{c}1000 \mathrm{~m}^{2} \\
700 \mathrm{~m}^{3} / \text { year } \\
\text { From } 0.9 \text { to } 0.6 \\
30 \\
210 \mathrm{~kg} / \text { year }\end{array}$ \\
\hline
\end{tabular}


Table 1. Cont.

\begin{tabular}{|c|c|c|c|}
\hline Action & Title & Indicators & $\begin{array}{l}\text { Quantification of Results } \\
\text { Expected (Minimum } \\
\text { Requirement) }\end{array}$ \\
\hline 4 & $\begin{array}{c}\text { De-waterproofing and } \\
\text { implementation of Sustainable Urban } \\
\text { Drainage System (SuDS) }\end{array}$ & $\begin{array}{l}\text { Increase in the de-waterproofed area } \\
\text { Subtraction of volume to surface runoff } \\
\text { Improvement of the runoff coefficient } \\
\text { Increase in planting } \\
\mathrm{CO}_{2} \text { absorbed }\end{array}$ & $\begin{array}{c}1500 \mathrm{~m}^{2} \\
1000 \mathrm{~m}^{3} / \text { year } \\
\text { From } 0.9 \text { to } 0.6 \\
14 \\
100 \mathrm{~kg} / \text { year }\end{array}$ \\
\hline 5 & $\begin{array}{c}\text { Improvement of the sewerage system } \\
\text { through SUDs }\end{array}$ & $\begin{array}{l}\text { Increase in the de-waterproofed area } \\
\text { Subtraction of volume to surface runoff } \\
\text { Improvement of the runoff coefficient }\end{array}$ & $\begin{array}{c}700 \mathrm{~m}^{2} \\
490 \mathrm{~m}^{3} / \text { year } \\
\text { From } 0.9 \text { to } 0.6\end{array}$ \\
\hline 6 & $\begin{array}{l}\text { Redevelopment of a section of the } \\
\text { Cisnara stream }\end{array}$ & $\begin{array}{c}\text { Improvement of the flood } \\
\text { lamination capacity } \\
\text { Increase in re-naturalized wetlands } \\
\text { Increase in rehabilitated area with } \\
\text { new forest } \\
\text { Increase in planting } \\
\mathrm{CO}_{2} \text { absorbed }\end{array}$ & $\begin{array}{c}2000 \mathrm{~m}^{3} \\
1500 \mathrm{~m}^{2} \\
2800 \mathrm{~m}^{2} \\
375 \text { trees, } 188 \text { shrubs } \\
2800 \mathrm{~kg} / \text { year }\end{array}$ \\
\hline 7 & $\begin{array}{l}\text { Hydraulic forestry intervention on } \\
\text { the Serenza stream }\end{array}$ & $\begin{array}{l}\text { Improvement of the safety of the banks of } \\
\text { the stream and the bridge-gallery } \\
\text { Naturalistic upgrading of the banks }\end{array}$ & $\begin{array}{l}\text { Qualitative estimates } \\
\qquad 12 \mathrm{~m}\end{array}$ \\
\hline 8 & $\begin{array}{c}\text { Hydraulic forestry intervention on } \\
\text { the Valletta stream }\end{array}$ & $\begin{array}{l}\text { Naturalistic upgrading of the banks } \\
\qquad \mathrm{CO}_{2} \text { absorbed }\end{array}$ & $\begin{array}{c}300 \mathrm{~m} \\
3750 \mathrm{~kg} / \text { year }\end{array}$ \\
\hline 9 & $\begin{array}{c}\text { Conservation and enhancement of } \\
\text { moorland habitats }\end{array}$ & $\begin{array}{l}\text { Improvement of heathland habitats } \\
\text { Improvement of the forest }\end{array}$ & $\begin{array}{l}3.5 \text { ha } \\
8 \text { ha }\end{array}$ \\
\hline 10 & $\begin{array}{c}\text { Forest improvement and containment } \\
\text { of exotic species }\end{array}$ & Improvement of forest structure & $\begin{array}{l}4.6 \text { ha } \\
530 \text { removals of non-native } \\
\text { plants }\end{array}$ \\
\hline 11 & Renaturalization of the Biulè tank & Increase in re-naturalized wetlands & $3600 \mathrm{~m}^{2}$ \\
\hline 12 & Cycle-pedestrian track with SuDS & $\begin{array}{c}\text { Implementation of a new } \\
\text { cycle-pedestrian track } \\
\text { Subtraction of volume to surface runoff } \\
\text { and/or sewerage system } \\
\text { Improvement of runoff coefficient } \\
\text { Increase in cycling users } \\
\text { Traffic reduction and air quality } \\
\text { improvement }\end{array}$ & $\begin{array}{l}\qquad 1.5 \mathrm{~km} \\
2600 \mathrm{~m}^{3} / \text { year } \\
\text { From } 0.9 \text { to } 0.6 \\
\text { Qualitative estimates } \\
\text { Qualitative estimates }\end{array}$ \\
\hline 13 & Cycle-pedestrian track with SuDS & $\begin{array}{c}\text { Implementation of a new } \\
\text { cycle-pedestrian track } \\
\text { Subtraction of volume to surface runoff } \\
\text { Improvement of runoff coefficient } \\
\text { Increase in cycling users } \\
\text { Traffic reduction and air quality } \\
\text { improvement }\end{array}$ & $\begin{array}{c}180 \mathrm{~m} \\
2600 \mathrm{~m}^{3} / \text { year } \\
\text { From } 0.9 \text { to } 0.6 \\
\text { Qualitative estimates } \\
\text { Qualitative estimates }\end{array}$ \\
\hline 14 & Support on request for funding & $\begin{array}{c}\text { Report on the availability of calls for } \\
\text { funding at the national and European level } \\
\text { Implementation of a monthly newsletter on } \\
\text { European design issues } \\
\text { Implementation of a project proposal on } \\
\text { funding calls at European level } \\
\text { Implementation of a project proposal on } \\
\text { regional/national funding calls }\end{array}$ & $\begin{array}{l}1 \\
1 \\
1\end{array}$ \\
\hline
\end{tabular}


Table 1. Cont.

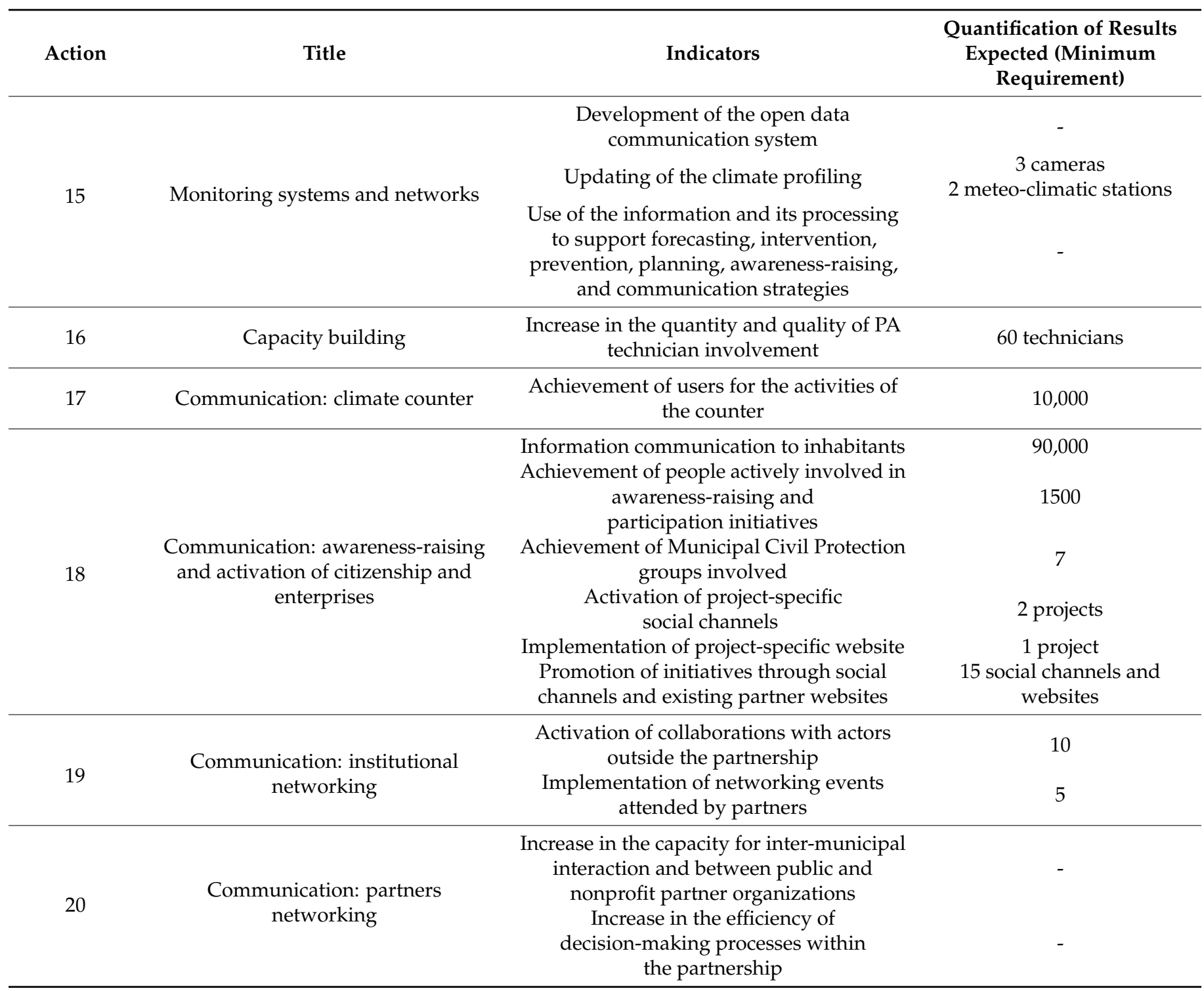

\subsection{Mainstreaming in Local Planning Tools}

The revision of urban planning tools serves to mainstream the action of municipalities in local and supra-local inter-municipal government choices so that they consider the issues of adaptation and mitigation to CC in the tools and processes of the territorial government (Table 2). 
Table 2. Spatial planning tools selected by the local administrations for in-depth analysis to the mainstream.

\begin{tabular}{|c|c|c|}
\hline $\begin{array}{l}\text { Municipalities and/or } \\
\text { Park Authority }\end{array}$ & Planning Tool & Guidelines to Be Included in the Plans \\
\hline \multirow[t]{2}{*}{ Bovisio Masciago } & Local Government Plan & $\begin{array}{c}\text { Promote planning that minimizes and compensates the } \\
\text { waterproof surface } \\
\text { In the survey framework, reference should also be made to a study of } \\
\text { territorial vulnerability arising from climate change }\end{array}$ \\
\hline & Green Regulation & $\begin{array}{l}\text { Integrate the Green Regulation with the definition of the most } \\
\text { suitable species for climate change } \\
\text { Consider climate change in urban green area design criteria }\end{array}$ \\
\hline Cesano Maderno & Green Regulation & $\begin{array}{l}\text { Consider climate change in urban green area design criteria and } \\
\text { consider measures to renationalize urban green areas } \\
\text { Promote sustainable urban drainage measures and ensure the } \\
\text { protection of remaining natural areas within the urban area } \\
\text { Integrate the definition of the species best suited to climate change }\end{array}$ \\
\hline \multirow[t]{2}{*}{ Meda } & Building Regulation & $\begin{array}{c}\text { Provide for greater adaptability and mitigation in new interventions } \\
\text { and restructuring } \\
\text { Define a Building Reduction Index to increase the response to } \\
\text { heatwaves and urban floods }\end{array}$ \\
\hline & Rules Plan & $\begin{array}{l}\text { Encourage action to adapt to climate change in the urban } \\
\text { environment. Contribute to the reduction in hydraulic risk and } \\
\text { de-waterproofing }\end{array}$ \\
\hline \multirow{3}{*}{ Varedo } & Building Regulation & Integrate the definition of the species best suited to climate change \\
\hline & Rules Plan & $\begin{array}{l}\text { Promote urban regeneration by encouraging adaptation to climate } \\
\text { change in the urban environment } \\
\text { Contribute to the reduction in hydraulic risk and de-waterproofing }\end{array}$ \\
\hline & Green Regulation & $\begin{array}{l}\text { Increase the capacity for territorial cohesion by laying down specific } \\
\text { rules to provide for greater capacity for adaptation and mitigation in } \\
\text { new interventions and restructuring } \\
\text { Define a Building Reduction Index to increase the response to } \\
\text { heatwaves and urban floods }\end{array}$ \\
\hline \multirow{3}{*}{ Groane Park } & Forest Steering Plan & $\begin{array}{l}\text { Provide for the preparation of the Plan for the Park's municipalities } \\
\text { in the province of Milan } \\
\text { Activate a technical discussion table with the province in order to } \\
\text { obtain the data of the draft plan under preparation }\end{array}$ \\
\hline & Forest Management Plan & $\begin{array}{l}\text { Provide for the revision of expired plans, with updated mass and } \\
\text { species data and management proposals }\end{array}$ \\
\hline & Agricultural sector plan & $\begin{array}{c}\text { Revision and updating of the Plan with extension to the extension } \\
\text { part of the Park } \\
\text { Update of the census of agricultural activities }\end{array}$ \\
\hline
\end{tabular}




\section{CLIMATE TRANSITION STRATEGY "LA BRIANZA CAMBIA CLIMA"}

\section{Revision of urban planning instruments}

Goals

Climate change adaptation and mitigation

\section{Search for funding}

4

Development of networks and tools for climate monitoring

Capacity building and technical training

6

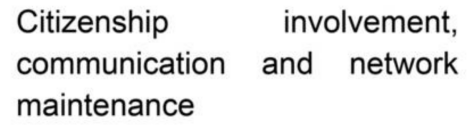

Actions

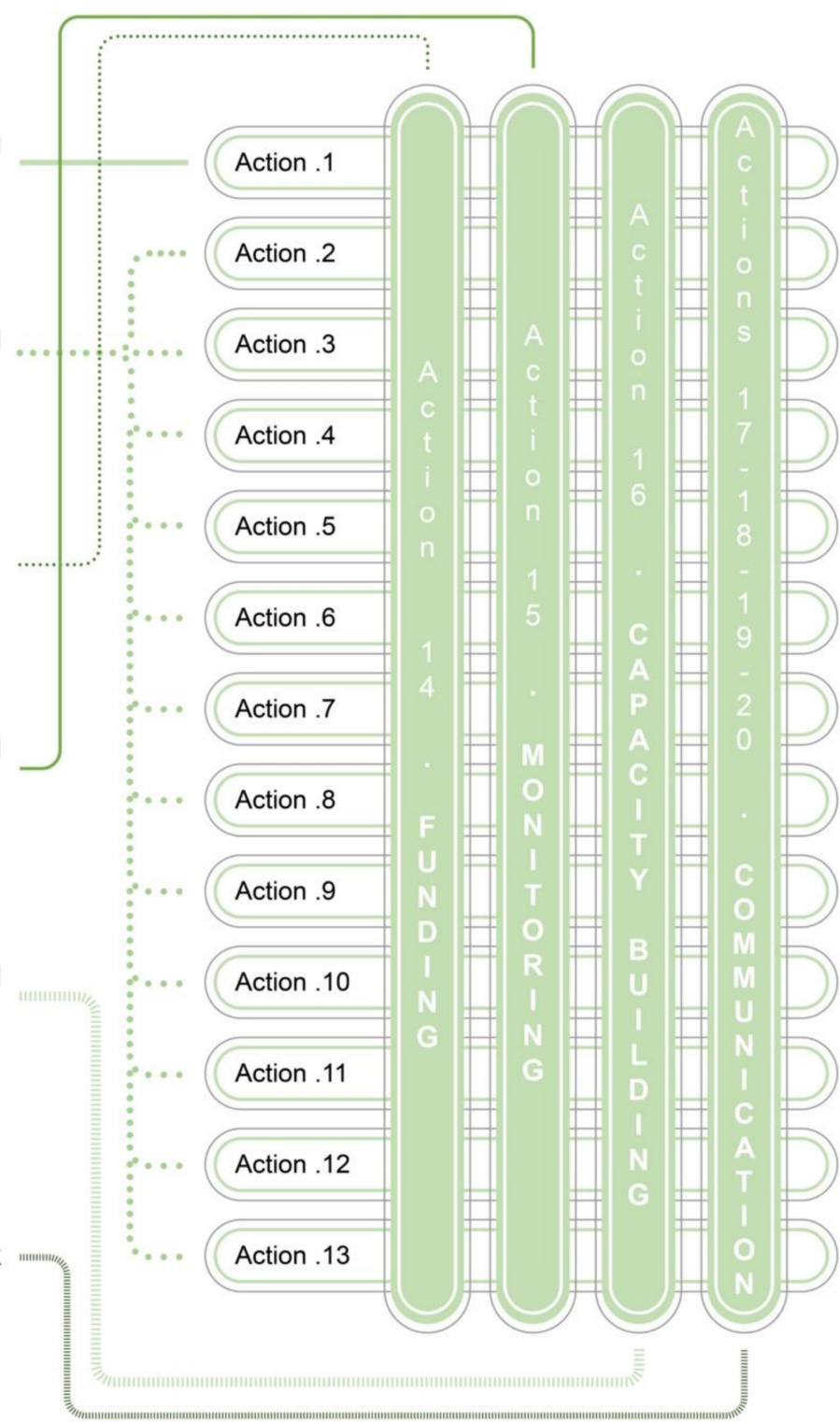

Figure 4. Goals for the CTS actions.

\section{Discussion}

In recent years, climate change adaptation issues have begun to permeate environmental planning and assessment practices with increasing awareness and effectiveness [26], but they also play an increasingly important and central role in the public debate and the commitment of civil society and the third sector. The Climate Transition Strategy built for West Brianza and discussed in this paper was conceived and constructed as an operational tool able to directly affect all decision-making processes of the public administration and indirectly those of the private sector. The gaps initially identified were overcome and a linear and coordinated process was guaranteed thanks to a clear process, a defined methodology, and the constant support of Fondazione Cariplo. The CTS, thanks to its important territorial information base, organized around the identification of the main climatic criticalities, has 
allowed the definition of adaptation goals, the construction of a medium- and long-term strategic vision, and the direct knowledge of the territorial context.

The measures identified for West Brianza have taken into account the superordinate regulatory and strategic context that, at regional, national, European, and global levels, already indicates the paths to be taken to make territories more adaptive, territorializing them according to the needs and opportunities of the reference context. The CTS has therefore been the activator of the partnership, trying to integrate and harmonize the partners' needs to make the process more impactful for the territory and more transformative for territorial and large-scale strategic planning. In this case, the CTS was able to fill the gap of the Municipalities' knowledge of a coherent and updated cognitive framework, providing:

- A high level of knowledge of the territorial context of reference concerning the goals of the F2C project;

- A wide description of activities consistent with the territorial context, innovative, and replicable;

- It was able to work in an inter-municipal and coordinated perspective, providing a global solution approach guaranteeing adequate involvement of each partner and a suitable governance structure of the project, able to remain on time;

- It provided a solid and credible vision of the territory in the medium-long-term concerning climate change;

- Fondazione Cariplo guaranteed adequate economic resources for the implementation of the actions contained in the CTS able to activate a cascade of new lines of funding.

To implement these processes, the context of aggregated municipalities is a particularly favorable network. Municipalities possess some important tools to deal with the impacts of climate change and it is at the local level that there is a complete and tangible perception of the territory's vulnerabilities and the most relevant and urgent dangers. Developing reasoning also at an inter-municipal scale can, therefore:

- Provide a broader context for action: bringing several municipalities together for a unified purpose or with an agreed direction in both the analysis and the resolution of critical issues and gaps can help local authorities make up for the lack of staff and resources they often face;

- Increase the effectiveness of actions: the impacts of climate change may involve several municipalities and areas not necessarily separated by administrative borders. Thinking and implementing integrated and homogeneous actions among municipalities can increase their effectiveness and efficiency, contributing to the virtuous management of economic and personnel resources, as well as materials;

- Optimizing resources: providing integrated responses to several municipalities facing similar gaps related to the management of climate change impacts can optimize the use of resources, but also the retrieval of regional, state, and European funds and contributions, which increasingly reward territorial aggregation and partnerships in the development of local strategies.

Climate transition processes at the local level are very difficult to initiate. It has been shown that the support of a Foundation that supports the process both economically and with technical and scientific accompaniment can be fundamental for implementing sustainable development and climate transition policies that are stabilized in local planning and thus capable of profoundly changing territorial attitudes. FC accompanied the entire methodological process, but technical support arrived only in Step II and Step III, while the partnerships defined the project proposal themselves in Step I. In this way, the technical support provided by universities and research institutions proved useful in guaranteeing method-logical rigor and a linearity of action to the process, but also in making it more effective and efficient. Moreover, the external experts are not part of the Inter-municipal Steering Committee but have the task of making this body as autonomous as possible and capable of moving forward in a durable and effective manner. The validation of the effectiveness of the methodology that occurred through participation in the drafting of the 
CTS with all the stakeholders involved was considerably important. All five steps were constructed with the different stakeholders at various times and were also verified with the Technical Scientific Committee. This specificity suggests the fact that this methodology can be applied independently in other territories as well. However, the role of a funding body or reward mechanism that facilitates the choice to initiate Climate Transition Strategies at the local level remains important. Finally, the monitoring plan-coordinated by the Cabina di Regia - of the effectiveness and efficiency of the CTS is also fundamental. The monitoring will highlight any slowdowns in implementation and/or unexpected effects and then be able to suggest the re-evaluation or recalibration of some actions and the CTS in a continuous process of revision.

\section{Conclusions}

Despite numerous and growing efforts throughout Italy, it is not yet clear how and when local governments can develop and implement in a structured way policy and project actions related to adaptation and mitigation. On the other hand, there is a clear need for these strategies to be linked both to changing patterns of behavior and development and be anchored in strategic planning at all levels.

One of the main gaps that still limits a widespread implementation of adaptation processes on the national territory is the fact that they continue to be entrusted to the political will that, depending on sensitivity, may or may not choose to invest time and resources in the implementation of sustainable and resilient solutions, but also to the lack of a concrete and shared strategic guidance tool. A direct consequence of this is the fact that, currently, in Italy, only large cities, such as Milan, Venice, and Bologna, have developed their own adaptation plans and, in any case, are always on a voluntary basis.

The definition of a Climate Transition Strategy such as the one imagined by the territory of "La Brianza Cambia Clima" can put in the system the policies that have been carried out for years in the area, helping to bridge the gaps that administrations often encounter in the implementation of adaptation processes to CC. The construction of the CTS acquires, therefore, a particularly significant role of coordination between the goals of the vast area and local action policies. The process must be planned systematically and managed in coordination between the various territorial bodies that must work together rather than separately. In this way, the Strategy can give stability, coherence, and continuity to adaptation processes involving different stakeholders and sectors of public administration and also to promote the implementation and multidisciplinarity of policies for territorial resilience on a large scale. To further strengthen the ability to respond and generate multiple local and large-scale benefits, the CTS is accompanied by the implementation of widespread interventions, the review of existing planning tools, the promotion of good practices for adaptation and mitigation to $\mathrm{CC}$ among citizens, and the activation of training and mutual exchange between public administrations. The method described therefore offers the opportunity for local authorities, even small or medium size, to act in a coordinated and inter-municipal way, in order to achieve a real transition to the resilience of the territories in the medium- to long-term.

In this context, it is also important to understand-also by considering the gaps that small- and medium-sized municipalities are having in defining projects for the Recovery and Resilience Plan-how to support small- and medium-sized municipalities such as those described here that suffer from a lack of planning skills, technical knowledge, and human resources. The CTS in question, for the first time in Italy and particularly at the inter-municipal level, has defined a process by adapting international methodological guidelines, creating shared, lasting, and truly transformative solutions. 
Author Contributions: Conceptualization, E.F.; methodology, G.L. (Giovanni Litt), E.F., F.M. (Filippo Magni) and G.L. (Giulia Lucertini); validation, F.M. (Francesco Musco); formal analysis, G.L. (Giovanni Litt) and E.F.; investigation, G.L. (Giovanni Litt), E.F., F.M. (Filippo Magni) and G.L. (Giulia Lucertini); resources, G.L. (Giovanni Litt), E.F. and F.M. (Filippo Magni); data curation, E.F. and F.M. (Filippo Magni); writing—original draft preparation, G.L. (Giovanni Litt); writing-review and editing, E.F., F.M. (Filippo Magni) and G.L. (Giulia Lucertini); visualization, E.F.; supervision, F.M. (Francesco Musco), F.M. (Filippo Magni) and G.L. (Giulia Lucertini); project administration, F.M. (Francesco Musco); funding acquisition, F.M. (Francesco Musco). All authors have read and agreed to the published version of the manuscript.

Funding: This research received no external funding.

Conflicts of Interest: The funders had no role in the design of the study; in the collection, analyses, or interpretation of data; in the writing of the manuscript, or in the decision to publish the results.

\section{Appendix A}

The Call for Ideas "Strategia Clima" is issued by the Environment Area within the project "F2C—Fondazione Cariplo per il Clima", Action Plan "Promoting environmental sustainability at local level". The Call aims to promote measures of mitigation and adaptation to CC (reduction in climate-altering emissions, mitigation of the impacts of extreme weather phenomena, and increase in natural heritage) and to raise awareness and dissemination of scientific knowledge on the impacts of global warming to institutions and citizens. In particular, it aims to select some areas within the reference territory of Fondazione Cariplo, to be involved, through a Technical Assistance service, in the co-design of a Climate Transition Strategy (CTS) and in the implementation of some measures. The Call has been built by Fondazione Cariplo together with a group of fifteen experts coming from different entities (Municipality, Metropolitan City, university, companies, associations, etc.), different geographical areas, and different academic or professional fields.

To lead to the implementation of the CTS, the Call provides three methodological steps, for each of which different topics and actors are foreseen (Figure A1):

1. Step I-Call for Ideas: the selection of partnerships formed by a municipal administration in the role of leader, at least one managing body of a naturalistic area of high importance for the protection of biodiversity and one private nonprofit body with experience in initiatives of citizen involvement in the field of environmental sustainability and sustainable lifestyles;

2. Step II-Technical Assistance for co-design: the selected areas have been admitted to the Technical Assistance service for the co-design of a Climate Transition Strategy at the local scale. This phase foresees the accompaniment by an interdisciplinary team of experts selected by the Foundation. This phase is also supported by a Technical Scientific Committee of Climate Strategy, which ensures the coherence of the specific projects with the general strategy of Fondazione Cariplo. It also contributes to identifying solutions to any criticalities that emerge during the implementation of the actions;

3. Step III-Implementation: in this step, some of the activities foreseen by the Climate Transition Strategy have been implemented by the partnership. 

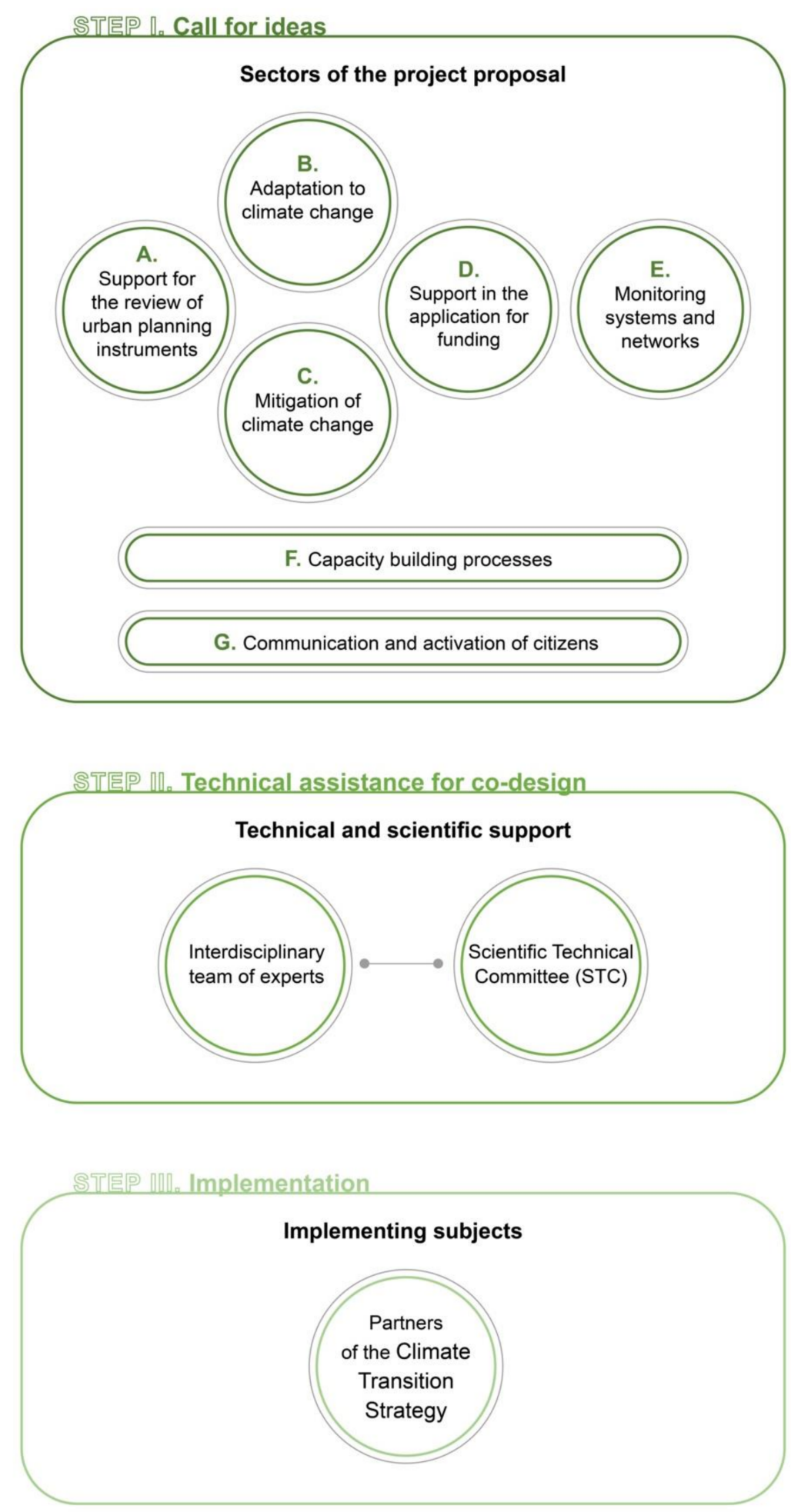

Figure A1. Topics and actors involved in the methodological framework of the Call for Ideas "Strategia Clima".

\section{Appendix A.1. Target Groups}

In Step I, project proposals will have to be presented by partnerships necessarily composed of: 
- A municipal administration in the role of leader, which will act to find solutions to citizens' needs arising from CC impacts (environmental, social, and economic) and will coordinate the actions of the partnership;

- A managing body of a naturalistic area, for the protection of biodiversity and ecosystem services essential to urban areas;

- A private nonprofit organization, with experience in citizen involvement initiatives in the field of environmental sustainability and sustainable lifestyles.

\section{Appendix A.2. Admissible Ideas}

In this first step, project ideas for a Climate Transition Strategy will be collected. This Strategy will have to have a strong impact on all decision-making processes of the public administration, for which a fair climate transition will have to be included both in the definition of new local policies and in the allocation of public resources and implementation of interventions. In particular, the actions identified in the CTS will have to be included in the ordinary or extraordinary planning of the public administrations involved. Moreover, the Strategy should be able to actively involve the project partners, the different stakeholders, and all citizens.

Project ideas should address the following areas:

- Description of the local main criticalities regarding CC impacts (from the point of view of each of the partners);

- Description of the proposal that should indicate the broad activities foreseen in the future climate strategy;

- Description of partners' roles and project governance;

- Summary list of initiatives already undertaken or about to be undertaken aimed at CC adaptation and mitigation in the project area;

- Strategic vision of the territory in the medium and long term (5 years and 10 years, respectively) in relation to CC impacts;

- $\quad$ Business plan of the project idea;

- Available economic resources.

In addition, the lead partner will have to identify, as project contact person, the Climate Manager, responsible for coordinating and monitoring the implementation of the Strategy and collecting the results of the various initiatives.

\section{Appendix A.3. Evaluation Criteria}

Preference will be given to ideas that demonstrate:

- A high level of knowledge of the reference territorial context in relation to the objectives of the F2C project;

- A description of activities that are coherent with the territorial context, innovative, and replicable;

- Adequate involvement of each partner and a suitable project governance structure;

- A solid and credible medium-long-term vision of the territory in relation to the CC;

- Substantial previous experience in the field of CC at the local scale;

- Own economic resources for the implementation of the actions contained in the Strategy;

- Broad support from other local actors and stakeholders, such as universities, research bodies, trade associations, and citizens' committees.

\section{Appendix B}

The table below (Table A1) synthetizes the main meetings that led to the final CTS implementation. It indicates, for each meeting, the date, the partners present, the topic of discussion, and the afference to one or more of the five methodological steps. Obviously, the numerous communications through phone calls and emails are excluded. 
Table A1. Steering Committee meeting for the implementation of the Climate Transition Strategy

(CTS) of "La Brianza Cambia Clima".

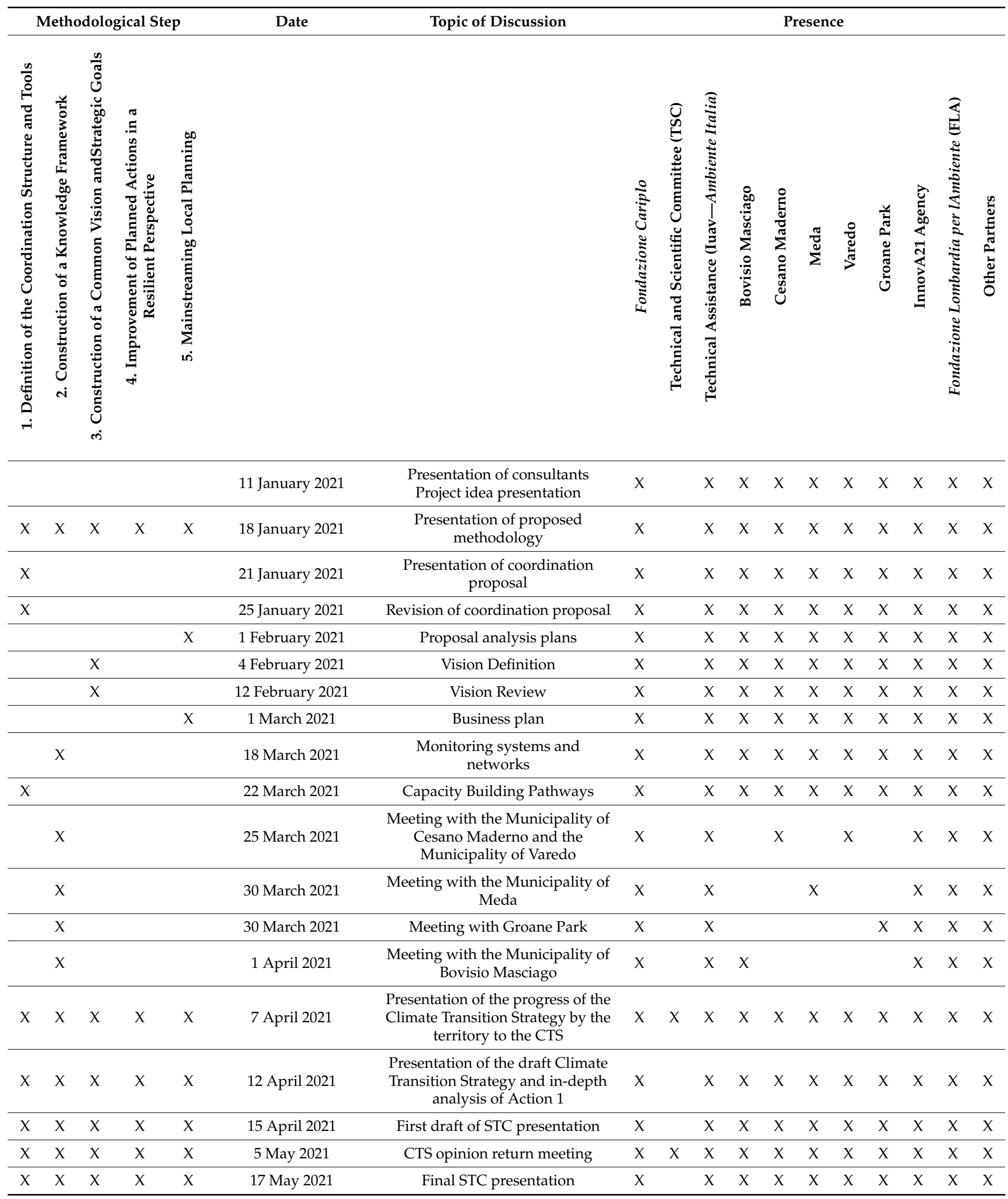




\section{References}

1. Allen, M.R.; Babiker, M.; Chen, Y.; de Coninck, H.; Connors, S.; van Diemen, R.; Dube, O.P.; Ebi, K.L.; Engelbrecht, F.; Ferrat, M.; et al. Summary for Policymakers. In Global Warming of $1.5^{\circ}$ C; IPCC: Geneva, Switzerland, 2018.

2. Ministero dell'Ambiente e della Tutela del Territorio e del Mare (MATTM). Strategia Nazionale di Adattamento ai Cambiamenti Climatici-SNACC; MATTM: Rome, Italy, 2014.

3. Lawrence, V. The Resilient City. Urban Rural. Sociol. 2007, 82, 57-65.

4. Patel, R.; Nosal, L. Defining the Resilient City; United Nations University Centre for Policy Research (UNU-CPR): New York, NY, USA, 2016.

5. Musco, F.; Maragno, D.; Magni, F.; Innocenti, A.; Negretto, V. Padova Resiliente; CORILA: Venice, Italy, 2016.

6. Mercalli, L. L'urgenza del Problema Ecologico: Uno Sguardo Dalla Scienza; Qiqajon: Biella, Italy, 2016; pp. 99-120.

7. MacKinnon, D. Resilient City; Elsevier: Amsterdam, The Netherlands, 2015; pp. 561-567. [CrossRef]

8. Brugmann, J. Financing the resilient city. Environ. Urban. 2012, 24, 215-232. [CrossRef]

9. Leichenko, R. Climate change and urban resilience. Curr. Opin. Environ. Sustain. 2011, 3, 164-168. [CrossRef]

10. Magni, F.; Musco, F.; Litt, G.; Carraretto, G. The Mainstreaming of NBS in the SECAP of San Donà di Piave: The LIFE Master Adapt Methodology. Sustainability 2020, 12, 10080. [CrossRef]

11. Measham, T.G.; Preston, B.L.; Smith, T.F.; Brooke, C.; Gorddard, R.; Withycombe, G.; Morrison, C. Adapting to climate change through local municipal planning: Barriers and challenges. Mitig. Adapt. Strateg. Glob. Chang. 2011, 16, 889-909. [CrossRef]

12. Reckien, D.; Salvia, M.; Heidrich, O.; Church, J.M.; Pietrapertosa, F.; De Gregorio-Hurtado, S.; D’Alonzo, V.; Foley, A.; Simoes, S.G.; Lorencová, E.K.; et al. How are cities planning to respond to climate change? Assessment of local climate plans from 885 cities in the EU-28. J. Clean. Prod. 2018, 191, 207-219. [CrossRef]

13. Arras, F.; Baruzzi, V.F.; Carraretto, G.; Santos, T.F.; Giordano, F.; Lapi, M.; Litt, G.; Luise, D.; Magni, F.; Marras, S.; et al DELIVERABLE AZIONE C3—Linee Guida per il Mainstreaming nei Gruppi di Comuni"—LIFE15 CCA/IT/000061 MASTER ADAPT_-"MainSTreaming Experiences at Regional and Local Level for Adaptation to Climate Change; European Commission: Brussels, Belgium, 2020.

14. F2C-Fondazione Cariplo per il Clima. Available online: https://www.fondazionecariplo.it/it/progetti/ambiente/f2cfondazione-cariplo-per-il-clima.html (accessed on 26 May 2021).

15. Jabareen, J. Planning the resilient city: Concepts and strategies for coping with climate change and environmental risk. Cities 2013, 31, 220-229. [CrossRef]

16. UNFCCC - United Nations Framework Convention on Climate Change. Compendium on Methods and Tools to Evaluate Impacts of and Vulnerability and Adaptation to, Climate Change; UNFCCC: Bonn, Germany, 2005.

17. Magni, F. Climate Proof Planning: L'adattamento in Italia tra Sperimentazioni e Innovazioni; Franco Angeli: Milan, Italy, 2019.

18. Bockel, L.; Smit, B. How to Mainstream Climate Change Adaptation and Mitigation into Agriculture Policies? FAO: Rome, Italy, 2009.

19. Vitale, C.; Meijerink, S. Understanding inter-municipal conflict and cooperation on flood risk policies for the metropolitan city of Milan. Water Altern. 2021, 14, 597-618.

20. LIFE MASTER ADAPT Project. Available online: https://masteradapt.eu (accessed on 3 October 2020).

21. LIFE METRO ADAPT Project. Available online: https://www.lifemetroadapt.eu/en/ (accessed on 13 December 2021).

22. LIFE VENETO ADAPT Project. Available online: https:/ / www.venetoadapt.it/en/ (accessed on 3 November 2021).

23. Contratto di Fiume Seveso. Available online: https://www.contrattidifiume.it/it/azioni/seveso/ (accessed on 27 February 2021).

24. Carta per L'azione dei Comuni del Bacino Idrico del Fiume Seveso verso L'adattamento Locale ai Cambiamenti Climatici. Available online: https:/ / masteradapt.eu/wordpress/wp-content/uploads/2019/10/Carta-del-Seveso_firmata.pdf (accessed on 5 December 2020).

25. Musco, F.; Maragno, D.; Litt, G.; Businaro, G. Common goods and climate proof cities: The LUCI approach. Boll. Del Cent. Calza Bini 2020, 20, 51-69. [CrossRef]

26. Arras, F.; Baruzzi, V.F.; Carraretto, G.; Santos, T.F.; Giordano, F.; Lapi, M.; Litt, G.; Luise, D.; Magni, F.; Marras, S.; et al. Linee Guida per L'implementazione del Mainstreaming Nelle Città Metropolitane"—LIFE15 CCA/IT/000061 MASTER ADAPT_-MAinSTreaming Experiences at Regional and Local Level for Adaptation to Climate Change; European Commission: Brussels, Belgium, 2019. 